\title{
DA SALA DE AULA TRADICIONAL À SALA DE AULA INVERTIDA: estratégias para a educação na era digital
}

\section{FROM THE TRADITIONAL CLASSROOM TO THE INVERTED CLASSROOM: strategies for education in the digital age}

\section{DEL AULA TRADICIONAL AL AULA INVERTIDA: estrategias para la educación en la era digital}

\author{
Leonides Pereira de Souza Guimarães ${ }^{1}$
}

1. Graduada em Pedagogia (UEGO). Doutorada em Ciências da Educação pela Universidad Colúmbia del Paraguay. E-mail: leonides04@ hotmail.com.

\begin{abstract}
RESUMO: A da Sala de Aula Invertida abre um leque de possibilidades para possíveis mudanças para a educação sem desconsiderar os desafios do método hibrido para o ensino e aprendizagem. As mídias disruptivas tem no ensino híbrido um forte aliado, impondo às práticas educativas uma trajetória, cujas relações educativas se pautam na horizontalidade, $\mathrm{e}$ cuja concentração, está na inversão dos domínios tradicionais que até então nortearam as práticas pedagógicas. A proposta em torno da Sala de Aula Invertida não é estática. Precisa de uma leitura do comportamento e das relações do nativo digital com o meio que o circunda a cada dia. O ensino hibrido enquanto prática educativa sustentável não pode ser pensada apenas como ação pontual, ela precisa se tornar um modo de vida e se constituir um processo consciente que repense o desenvolvimento de habilidades e a superação de limites a partir de cada ação desenvolvida. Reafirma-se que todas as parcerias são bem-vindas, conforme se destacou nos relatos com as experiências educacionais exitosas quanto a qualificação do processo de ensino híbrido, a sala de aula invertida.
\end{abstract}

Palavras-chave: Tecnologia digital; Metodologia Ativa; Estratégias de ensino; Estruturas de Aprendizagens.

\begin{abstract}
The Inverted Classroom opens up a range of possibilities for possible changes to education without ignoring the challenges of the hybrid method for teaching and learning. Disruptive media have a strong ally in hybrid education, imposing a trajectory on educational practices, whose educational relations are based on horizontality, and whose concentration is in the inversion of the traditional domains that until then guided the pedagogical practices. The proposal around the Inverted Classroom is not static. It needs a reading of the behavior and relationships of the digital native with the environment that surrounds him every day. Hybrid teaching as a sustainable educational practice cannot be thought of only as a one-off action, it needs to become a way of life and constitute a conscious process that rethinks the development of skills and overcoming limits based on each developed action. It is reaffirmed that all partnerships are welcome, as highlighted in the reports with successful educational experiences regarding the qualification of the hybrid teaching process, the inverted classroom.
\end{abstract}

Keywords: Digital technology; Active Methodology; Teaching Strategies; Learning Structures.
RESUMEN: El Aula Invertida abre un abanico de posibilidades para posibles cambios en la educación sin ignorar los desafíos del método híbrido de enseñanza y aprendizaje. Los medios disruptivos tienen un fuerte aliado en la educación híbrida, imponiendo una trayectoria a las prácticas educativas, cuyas relaciones educativas se basan en la horizontalidad, y cuya concentración está en la inversión de los dominios tradicionales que hasta entonces orientaban las prácticas pedagógicas. La propuesta en torno al Aula Invertida no es estática. Necesita una lectura del comportamiento y las relaciones del nativo digital con el entorno que lo rodea todos los días. La enseñanza híbrida como práctica educativa sostenible no puede pensarse solo como una acción puntual, necesita convertirse en una forma de vida y constituir un proceso consciente que replantee el desarrollo de habilidades y la superación de límites a partir de cada acción desarrollada. Se reafirma que todas las alianzas son bienvenidas, como se destaca en los informes con experiencias educativas exitosas en cuanto a la calificación del proceso de enseñanza híbrido, el aula invertida.

Keywords: $\quad$ Tecnología digital; Metodología Activa; Estrategías de Enseñanza; Estructuras de Aprendizaje. 


\section{INTRODUÇÃO}

A geração dos nativos digitais exige uma proposta educativa que articule diferentes modalidades de ensino e se possível, integre ao processo alguma tecnologia digital.

Isso, porque a geração dos nativos digitais, diferente das outras gerações, $\mathrm{X}$ e $\mathrm{Y}$, mantém uma relação satisfatória com as mídias digitais e a internet, não imaginando a vida sem elas.

Por entendermos que esta mesma geração não se adeque a modalidade tradicional de educação, também denominada pré-digital, se discutiu sobre tema "Da sala de aula tradicional à sala de aula invertida: estratégias para a educação na era digital", uma abordagem da sala de aula que busca inserir no plano educacional, a partir de um ciclo reverso, o ensino híbrido que mescla ao ensino tradicional e on-line.

Esta é uma proposta educacional emergente e muito promissora para o "mercado" educacional pósmoderno, uma vez que, a partir de um contexto físico interligado a uma experiência de aprendizagem online, alcançando em maior profundidade ao público estudantil colocando em evidencia modelos sustentados e/ou disruptivos.

A interação existente entre o objeto de estudo e a atualidade, conhecimento e intersubjetividade (individual e coletiva), encaminhou-nos para um estudo bibliográfico em um nível, onde não havendo aplicabilidade, não permite mensuração.

Em uma concepção geral, o estudo apresenta abordagem teórica sobre o método de ensino hibrido e suas implicações e de igual modo, a descrição de experiências exitosas, que completam o estudo da proposta.

As experiências nos permitiram concluir que este se trata de um método que requer dos envolvidos rupturas de velhos hábitos de trabalho, principalmente no que se refere ao uso da tecnologia no contexto educativo.

Acredita-se a partir do estudo, que a proposta da Sala de Aula Invertida abre um leque de possibilidades para possíveis mudanças para a educação sem desconsiderar os desafios do método hibrido para o ensino e aprendizagem.

\section{Descomplicando o panorama educativo para a geração do século XXI}

As tecnologias digitais têm exercido um papel importante na elaboração do conhecimento formal e não formal do indivíduo. Graças ao advento da internet um novo panorama educacional vem se construindo.

Não menos importante, portanto, mais inclusivo, tem em vista que "o perfil do estudante mudou, e a escola vive em um contexto socioeconômico que impõe expectativas continuamente elevadas". (BARBOSA; MOURA, 2013, p. 50). 
Tendo em vista este perfil, e as formas de comunicação e aprendizagem em um universo disruptivo, tem-se que o grande desafio da educação, conforme descreve Kenski (2013), Coll (2013), Valente (2014) entre outros, está na busca por novas estratégias educacionais inovadoras que potencializem a aprendizagem.

Estas práticas inovadoras, conforme descreve Moran (2015, p. 17-18), apresentam como 'ponto de partida" a combinação de "atividades, desafios e informação" que contextualizados promovem a aprendizagem a partir da pesquisa.

Neste caso, ganha ênfase a abordagem metodológica da Sala de Aula Invertida. Esta metodologia agrega avanços tecnológicos e a partir deles, busca "minimizar a evasão e o nível de reprovação dos estudantes dos referidos institutos". (VALENTE, 2014, p. 87).

Dentro desta perspectiva, ocorre de modo vibrante, uma transição da lógica de distribuição de informação para àquela de construção e interação ? ou seja, de Tecnologia de Informação e Comunicação (TIC) para a Tecnologia de Autoria e Construção (TAC) ?, na qual o papel do professor é ser mediador dentro de uma proposta curricular de alta estimativa, isto é, voltada para a capacidade de resolução de problemas. (SCHLÜNZEN JÚNIOR, 2015)

Consoante a este pressuposto que destaca como tendências de mercado para educação a busca de novas estratégias de ensino, tem-se que o que falta mudar é o jeito de ensinar, "porque as cabeças dos que têm a tarefa de 'aprender', não há dúvidas, já estão abertas para o mundo, via internet, via redes sociais". (LOPES, 2015, p. 6)

Prado (2015) acrescenta, "embora os recursos multimídias sejam usados" faz-se necessário resgatar o estudante de uma postura passiva para uma postura mais ativa no que tange a sistematização e produção do conhecimento.

\subsection{Sala de Aula Invertida: relação entre estratégia de ensino, inovação pedagógica}

O termo Sala de Aula Invertida é tradução usada de uma série de expressões em inglês, tais como inverted classroom; flipped classroom; flipped teaching ou flip teaching; reverse teaching; flipping the classroom ou flip the classroom. No Brasil, pesquisadores deste método optaram pela utilização da expressão flipped classroom.

Flipped Classroom é um modelo que tem suas raízes no ensino híbrido, conhecido como blended learning ou b-learning e teve seu conceito desenvolvido a partir de experiências $e$-learning ${ }^{1}$, ou seja, de

\footnotetext{
${ }^{1}$ Desde a década de 1990, o mercado empresarial vem adicionando a letra " e-" a um conjunto de palavras para designar tudo que é eletrônico. Mas significa também era digital e internet. Masie (2001c apud LIMA; CAPITÃO, 2003, p. 35) sugere três dimensões para o significado da letra —e: Experiência, Extensão e Expansão.
} 
instruções apresentadas em um dispositivo digital, como um computador ou dispositivo móvel que se destina a apoiar a aprendizagem. (CLARK; MAYER, 2011, p. 8, tradução nossa).

As mídias disruptivas ${ }^{2}$ tem no ensino híbrido um forte aliado, impondo às práticas educativas uma trajetória, cujas relações educativas se pautam na horizontalidade, e cuja concentração, está na inversão dos domínios tradicionais que até então nortearam as práticas pedagógicas.

Por isso, as mídias disruptivas abrem concessões para aplicação de novos métodos de trabalho, resinificando o ensino e impondo a trajetória do processo de aprendizagem um novo ritmo. (HORN; STAKER, 2015).

\subsection{Estratégias para implementação da Sala de Aula Invertida}

A implementação da Sala de Aula Invertida toma por base todas as concepções descritas até aqui. Neste caso, reforça-se atenção ao princípio da realidade social e acadêmica que envolve cada participante e que não podem ser esquecidos durante o desenvolvimento do método, como os interesses de aprendizagem e as crenças individuais de cada sujeito. (SCHULUNZEN, 2016).

As crenças dos indivíduos envolvidos são importantes no processo ensino-aprendizagem por exercerem influência direta na motivação e ações de alunos, professores e demais envolvidos no processo, conceituando-as como "uma forma de pensamento" construto da realidade e que encorajam os indivíduos a enfrentar o que não conhecem ou, possivelmente os desmotive de querer realizar algo. (BARCELOS, 2006. p. 18).

Quando as estratégias de ensino buscam responder a estas crenças, possivelmente, ela estará aderindo a um projeto educacional, que em sua abrangência, articulam um projeto de integração social e formação humanística com vistas à construção do conhecimento.

É nesta amplitude educativa, que supostamente se encontra suporte para desenvolvimento da modalidade educacional híbrida, espaço que agrega uma sala de aula física e um ambiente virtual de aprendizagem e que propicia momentos de interação presencial e a distância. Desta forma, há um redimensionamento da do papel do professor e do aluno.

O professor se apresentará como um guia ou moderador da aprendizagem, planejando o conteúdo a ser estudado externamente e mediador das discussões gerando interpretações visuais e promotor de vivência dos conteúdos apreendidos através de atividades lúdicas e de produção.

\footnotetext{
${ }^{2}$ Mídias disruptivas são aquelas mídias adaptáveis, acessíveis e convenientes como forma de ajudar profissionais que lidam com redes sociais ou no caso do estudo em específico, reinventar a prática pedagógica de forma surpreendente e independente.
} 
Já os alunos, precisarão ser proativos e autônomos, se dedicarem aos estudos fora da sala de aula e em conexão com a internet, acessar videoaulas, e-books, hipertextos, powerpoints, filmes, áudios, games, podcasts, tutoriais, plataformas virtuais e outros meios de pesquisar, estudar, gerar conteúdos e vivenciar experiências significativas.

Ao método Sala de Aula Invertida, é importante que, antecipadamente o professor tenha em conta os seguintes questionamentos: quais os suportes que a minha instituição disponibiliza? Quais são os suportes que os alunos têm acesso? Quais conteúdos os alunos devem aprender? Quais serão as possíveis dúvidas dos alunos? Como gerar uma experiência significativa associando o conteúdo programático a este método? Como resgatar aqueles que não estudaram o conteúdo previamente?

Respondidas a estas questões, a aplicação do método deve compreender estratégias ou procedimentos, cujas técnicas estão na relação mediada e projetada para acontecer entre professor e aluno, e que determinem claramente onde ambos desejam chegar.

A proposta da sala de aula invertida, a partir do conceito de ensino híbrido, se faz a partir da combinação de dois momentos: o primeiro é o inicial da aprendizagem, externo à sala de aula e on-line; já o segundo momento para reflexão dos conteúdos aprendidos, a aula é dentro do espaço físico da sala.

Para o primeiro momento, há a elaboração do formato de conteúdo (vídeo aula, podcasts e outros murais virtuais, apresentações em flash, jogos, atividades de reflexão entre outros) disponibilizado aos alunos.

Para o segundo momento, vamos pensar em técnicas que promovam interação em sala de aula, a fim de expor o conteúdo aprendido, sentir na prática e tirar dúvidas do grupo único de alunos, saindo do mecanicismo tradicional e partindo para o modelo híbrido personalizado.

Jogos didáticos, tempestade de ideias (brainstorming), mapas conceituais coletivos, resolução de problemas, estudo de caso e júri simulado, projetos, oficinas ou encenação, são algumas opções que podem ser adequadas por promoverem formas de aprendizagem coletiva e colaborativa.

Ressalta-se que as técnicas citadas não devem ser escolhidas aleatoriamente, mas considerar a realidade específica dos alunos e sua totalidade social, pois quanto mais equilibrado for o processo, maior a possibilidade de "acesso, troca, recombinação de ideias, experiências e sínteses", oportunizando ao aluno o controle de parte do ensino onde possa deliberadamente organizar seu ritmo de aprendizagem. (BACICH et al., 2015, p. 32).

Deste modo, cabe-nos categorizar o que é e o que não é o processo de hibridação do ensino, para que não haja dúvida sobre como desenvolvê-lo e que técnicas utilizar para a dinamização do ensino, conforme destaca Horn e Staker (1995).

Não se caracteriza ensino hibrido: 
- Ensino on-line, onde o estudante acessa um Ambiente Virtual de Aprendizagem (AVA);

- Não é utilização de um sistema de gestão de aprendizagem para comodidade do professor;

- Não é a conexão entre professores e alunos por videoconferência (todos ao mesmo tempo).

- Não é inserir jogos para alunos sem coleta de dados para melhorar o projeto de ensino e aprendizagem. Isso é inútil e se converte apenas na dimensão tecnológica do ensino.

Caracteriza-se uma proposta para implantação do ensino hibrido:

- Criação de uma "plataforma" distinta preparado pelo professor para que realize a "tarefa de casa".

- É aula gravada, para que possa pausar o professor e estabelecer seu próprio ritmo de aprendizagem.

- É uso de recursos tecnológicos para coleta de dados sobre a aprendizagem.

Após caracterizar o ensino híbrido, o apresentamos agora de maneira crítica e criativa, a partir do modelo de rotação, que engloba distintos modelos, incluindo a sala de aula invertida, conforme apresenta Horn e Staker (1995).

O Modelo de Rotação, engloba um programa alternativo que permite que o aluno aprenda por meio de um cronograma fluído e personalizado que inclui outros métodos como Rotação por Estações, Laboratório Rotacional, Sala de Aula Invertida (objeto em estudo) e Rotação individual.

O método Sala de Aula Invertida busca considerar a relação entre estratégia de ensino e inovação pedagógica, reposicionando educação e produção de conhecimento, sobretudo, a ampliação dos ambientes de aprendizagem.

Nesta panorâmica, avaliação dos alunos poderá considerar as técnicas e estratégias vivenciadas, práticas e seus fins, para legitimar todo o percurso pedagógico realizado.

\subsection{Inovação pedagógica: processos educacionais efetivos e sustentáveis}

A Organização das Nações Unidas para a Educação, a Ciência e a Cultura (UNESCO), definiu em documento o período de 2005 a 2014 como sendo a Década das Nações Unidas da Escola para o Desenvolvimento Sustentável por, em nosso entendimento, associar o ideal de globalização com projetos de desenvolvimento sustentável economicamente em educação.

Confirmando o nosso entender, a UNESCO no documento diz que a educação inspira a crenças que cada pessoa tem, o poder e a responsabilidade de introduzir mudanças positivas no mundo. Neste sentido, 
vale refletir que a aprendizagem não é constituída somente no ambiente escolar e também não se encerra nele.

Assim, o ensino deve atender "o desenvolvimento de capacidades cognitivas básicas e instrumentos em detrimento do desenvolvimento de sua força criativa e de sua autonomia intelectual e política", formando cidadãos conforme "os saberes específicos e locais ao conjunto de saberes sociais." (ARAÚJO, 2015, p. 63).

A essência desta informação desperta em nós pesquisadoras e professoras, o sentimento de que a aprendizagem deve ser para toda a vida e não para um período específico, presente e limitado, mas um fazer abrangente que ensine o estudante a ser, aprender, conhecer, fazer e conviver, a partir inclusive do seu esforço pessoal.

Entende-se, neste âmbito, que uma educação sustentável e efetiva, além de priorizar comportamentos e práticas sociais, se coloca a serviço da escola, como um todo ético-social e cultural.

Em todo esse processo educacional é importante entender que a educação busca desenvolver habilidades e competências para a vida, abandonando posturas estáticas e assumindo posturas mais dinâmicas tanto para se ensinar quanto para aprender.

Deste modo, o termo sustentabilidade aqui referente, encontra respaldo argumento descrito pela UNESCO (2005, apud MOREIRA 2008, p. 8) de que a sustentabilidade em um contexto mais amplo se prefigura através de [...] maneiras de se pensar o mundo e as formas de prática pessoal e social" que levam os indivíduos a se desenvolver com "valores éticos, autônomos e realizados" bem como, se desenvolver em "comunidades construídas em torno de compromissos coletivos, tolerância e igualdade".

Deste modo, as escolas enquanto "sistemas sociais e instituições participativas, transparentes e justas" requer de todos os sujeitos participantes, envolvimento e gestão de aprendizagem adequada, ou seja, uma pratica educativa que apresente resultados.

Assim, ao evidenciarmos o papel da educação e gestão dentro de uma perspectiva sustentável, destaca-se de acordo com Engelman et al. (2012, apud BECKER, 2015), que os gestores ao administrarem suas instituições, para que a educação seja suficiente, devem observar questões como

[...] localização geográfica, dimensão, condições do ambiente local, capacidade de aproveitamento de oportunidades, cooperação interinstitucional, capacidade de concretização de parcerias com entidades muito diferentes e outros aspectos. (ENGELMAN et al., 2012, apud BECKER, 2015, p. 619). 
Portanto, não há como idealizar projetos que englobem o desenvolvimento de práticas educacionais inovadoras, que autossustentáveis, sem verificar aspectos sociais, econômicos, culturais que circunda esta mesma comunidade escolar.

Desse modo, uma prática sustentável, preocupa-se com a criação de um ambiente de ensino, cujas ações integram habilidades cognitivas e sócio emocionais, abertura para novas ideias, colaboração e persistência e respeito às crenças individuais agregadas a sistematização do conhecimento.

Ganha ênfase, neste contexto, o uso de tecnologias, que enquanto elemento de mediação do processo de ensino e aquisição da aprendizagem, promovem uma ruptura, interrupção do curso normal de práticas de ensino positivistas.

Deseja-se com esta discussão, sobre práticas pedagógicas inovadoras e sustentabilidade educacional, refletir sobre o encurtamento de distâncias, conferindo mais agilidade e produtividade no mercado educacional, economizando recursos e reinventando estratégias educativas para o barateamento do ensino e efetivação da aprendizagem a partir de momentos on-line e presencial.

Estes momentos podem ser experimentados a partir da agregação das mídias e tecnologias digitais ao processo de ensino - tais como as redes móveis e os celulares smartphones, plataformas conversacionais, o uso da Computação em Nuvem ou memória on-line e Inteligência Artificial acessíveis e usuais.

Todos estes artefatos tecnológicos possibilitam a professores e alunos uma experiência imersiva qualitativa e que pode ser acessado de qualquer lugar sem a necessidade de pendrives ou disco rígido externo.

Outras tecnologias merecem destaque, mesmo sendo menos conhecidas, como Internet das Coisas, Big Data, Sistemas Cognitivos e Data Analysis, Event driven, Blockchain, entre outras.

Estes suportes motivam a qualidade do tempo, eficiência e oferecem soluções para diversos problemas, podendo ser usados estrategicamente em educação por de modo a promover experiências que contemplem percepções visuais, auditivas e táticas.

Por fim, destaca-se, neste contexto, os Ambientes de Aprendizagem Inteligentes (AAIs) que agregam os sistemas computacionais à educação e incorporam técnicas com Inteligência Artificial.

Estes Ambientes colocam os estudantes como coparticipantes do processo de aprendizagem através da interação deste, com elementos disruptivos, midiáticos e transmidiáticos.

A partir destas considerações, os Ambientes de Aprendizagem Inteligentes (AAIs) podem ser visualizados como uma organização mais genérica do que àquela dos Sistemas Tutores Inteligentes.

Logo, práticas pedagógicas sustentáveis não podem ser pensadas a partir de ações pontuais, elas precisam antes, ser agregadas a um modo de vida, pois conforme declara Moreira (2008, p. 20) "a 
sustentabilidade da humanidade terá como possibilidade efetiva apenas quando o controle social da produção, da circulação e do consumo estiverem sob o controle consciente".

Entende-se, a partir desta perspectiva, que a sustentabilidade em educação a partir de novas metodologias, se dá de maneira consciente, efetuando o barateamento do ensino a partir da troca de materiais impressos pelo uso de tecnologias digitais, garantindo menor produção de lixo seco.

Deste modo, o uso de materiais coletivos e individuais em dinâmicas presenciais, se dão em menor quantidade e podem ter destinos conscientes definidos pelos indivíduos ingressos no ambiente de ensino. Deste modo, práticas que minimizem os impactos sobre o ambiente, podem ser considerados sustentáveis em âmbito escolar. E no continuun destas reflexões, veremos algumas experiências exitosas e os desafios para a implantação da proposta da sala de aula invertida.

\section{A inversão da sala de aula: experiências exitosas}

Explicitamos anteriormente que, o método da Sala de Aula Invertida inverte a lógica da sala de aula tradicional e consiste em mudanças nos papeis de professores e alunos.

A dinâmica da sala de aula invertida está descrita pelo educador americano Salman Khan e relatada por dois professores de Química, Jonathan Bergmann e Aron Sams. De suas experiências, eles escreveram um livro, "Sala de Aula Invertida - Uma metodologia ativa de aprendizagem", pela Editora LTC, que em português, já alcançou no Brasil uma série de adeptos ao método.

A experiência desta dupla deu-se com a gravação de vídeos simples para ajudar seus alunos com mais dificuldades e ou faltosos. A experiência deu tão certo, que eles estenderam a todos e começaram a fazer conferências e formações para profissionais da educação de forma global.

Na perspectiva dos autores do método, Jonathan Bergmann e Aron Sams, esta forma de trabalho é interessante porque permite aos professores aproveitar melhor o tempo em sala de aula, personalizando o ensino.

O método alcançou prerrogativa no Brasil no ano de 2014. Neste mesmo ano, um curso foi organizado por Wilson Azevedo, diretor da Aquifolium Educacional e contou com a participação de Jonathan Bergmann. Este curso teve início no dia 9 de maio, com duração de três semanas e se deu sua terceira edição. (COSTA, 2016)

O impacto desta metodologia também foi notável nas aulas de espanhol da Universidade Federal da Integração Latino-americana (UNILA). Em entrevista ao site porvir.org, a professora Jorgelina Tallei conta que a experiência da Sala de Aula Invertida na disciplina de língua espanhola como Língua Adicional possibilitou aos alunos, alunos paraguaios, argentinos, bolivianos, peruanos e uruguaios a uma boa 
aprendizagem da língua e de igual modo, aprender novos costumes e culturas a partir da sala de aula invertida, articulado a pedagogia de projetos e uso de vídeos no site Youtube.

Outra experiência interessante ocorreu em uma escola estadual de Campinas. Nesta escola, o método foi empregado com a finalidade de melhorar o desempenho dos alunos em matemática. Todo o trabalho foi realizado no QMágico, uma plataforma de aprendizagem que ajudou a inverter a sala de aula. A experiência contemplou 14 turmas entre o ensino fundamental e médio.

Para a coordenadora do projeto na referida instituição, o emprego do método proporcionou um ganho significativo, cerca de $20 \%$ na melhora da aprendizagem no ensino de matemática e na interação entre professores e alunos. (LOPES, 2015).

Por conseguinte, outra experiência a ser relatada e que deu certo é a da professora de Ciências do Colégio Albert Sabin, em São Paulo, Thaís Arten. Ela também utilizou a plataforma Qmágico com suas turmas para desenvolver a Sala de Aula Invertida e segundo a professora, os alunos da sexta série, apresentaram melhoras em oito pontos, com relação à aprendizagem do período anterior. A experiência deu tão certo, que ela estendeu o uso da metodologia às séries posteriores.

Uma das questões pontuais, que segundo a professora contribuiu para o sucesso da metodologia, foi o fato de ela agregar ao processo de ensino ferramentas como hipertextos, podcasts, pesquisas e vídeos.

O método de Jonathan Bergmann e Aaron Sams, também foi testado e aprovado pelas melhores universidades do mundo, como Duke, Stanford e Harvard.

Em Harvard, nas disciplinas de cálculo e álgebra, os alunos inscritos em aulas invertidas obtiveram ganhos de até $79 \%$ na aprendizagem a mais, do que àqueles que cursaram o ensino tradicional.

Para o Massachusetts Institute of Technology (MIT), a Flipped Classroom constituiu-se fundamental para a instituição por se tratar de uma metodologia que permite ao professor aprofundar conteúdos com diferentes exercícios, estudos de caso e conteúdo.

Note-se que a interação e a interatividade proporcionada pela sala de aula invertida, ao despertar a motivação dos alunos, melhora hábitos de leitura e qualifica os índices da aprendizagem, um importante quesito a ser considerado por estas instituições.

Países como Finlândia, Singapura, Holanda e Canadá, também testam a eficiência ou ineficiência dos métodos ativos de aprendizagem, dentre eles a sala de aula invertida.

\subsection{Desafios para a implementação do método Sala de Aula Invertida}


Entre os benefícios, também existem os desafios que circundam a implementação da sala de aula invertida. Segundo Rodrigues et al. (2015) existem alguns pontos a serem considerados no momento de pensar esta implementação, como por exemplo, observar se não há resistência dos alunos quanto à nova metodologia. Neste caso, a adaptação pode ser longa.

Outro ponto a ser observado segundo os autores, é o desenvolvimento do nível cognitivo do estudante. Para eles, a falta de aula expositiva, pode ser vista pelo aluno como algo prejudicial a sua aprendizagem.

Anterior a estas questões, tem-se que se pensar a questão da marginalização tecnológica pois nem todos tem acesso a computador ou à internet, fator que limita a interação do estudante com o conteúdo e demais fontes de aprendizagem. Se o estudante não acessa o conteúdo em casa, ele não apresenta condições de participar das atividades de classe junto aos colegas.

Assim sendo, é de grande relevância o comprometimento do estudante nos momentos de estudo online, para que sua aprendizagem não seja comprometida.

Estas são questões pontuais que devem ser consideradas no momento do planejamento da inversão da sala de aula, e que se observadas promovem uma experiência exitosa. Ignorar estes aspectos, seria marchar contra a proposta da Metodologia Ativa, cuja proposta seria promover novas discussões e novos aprendizados.

\section{CONSIDERAÇÕES FINAIS}

Procurou-se com o desenvolvimento desta temática, apresentar uma abordagem teórica sobre a Sala de Aula Invertida, uma vez que o contexto educativo requer dos professores maior consciência, compromisso, criatividade e atualização das ações pedagógicas e educativas voltadas para o aluno da geração digital.

A mescla de ensino on-line e tradicional, proposta pelo ensino híbrido, nesta ordem, sugere baixo custo e melhor aproveitamento dos conteúdos educacionais. Neste contexto, conceitos desde a conscientização, responsabilidade social, liderança, confiança refletem sobre o projeto educativo que insere ao plano educacional novos procedimentos de ensino e aprendizagem com a inserção de mídias disruptivas.

O processo híbrido envolve uma mediação acentuada das tecnologias, e cujas as diretrizes orientadoras do processo, possibilitam estratégias de ensino com o foco direcionador na proatividade estudantil.

Várias são as possíveis técnicas e estratégias de ensino e nenhuma delas deve ser desconsiderada a priori, sem antes refletir sobre quais suportes a instituição de ensino e os alunos têm acesso. 
A proposta em torno da Sala de Aula Invertida não é estática. Precisa de uma leitura do comportamento e das relações do nativo digital com o meio que o circunda a cada dia. Assim, cabe-nos buscar fontes que nos expliquem e nos aproximem de suas realidades para que se possamos alcançar eficiência no processo educativo e de igual modo, em outras áreas de desenvolvimento.

Para finalizar, precisamos registrar que existem vantagens e também desvantagens para a implantação da inversão da sala de aula. O estudo apresenta-nos ainda outra questão que merece ser considerada: os indivíduos envolvidos no processo educacional estão dispostos a encarar o desafio?

O ensino hibrido enquanto prática educativa sustentável não pode ser pensada apenas como ação pontual, ela precisa se tornar um modo de vida e se constituir um processo consciente que repense o desenvolvimento de habilidades e a superação de limites a partir de cada ação desenvolvida.

Neste interim, todo processo deve antes de tudo, considerar a educação em si, como um ato de responsabilidade social. Reafirma-se que todas as parcerias são bem-vindas, conforme se destacou nos relatos com as experiências educacionais exitosas quanto a qualificação do processo de ensino híbrido, a sala de aula invertida.

\section{REFERÊNCIAS}

BACICH, L.; TANZI NETO, A.; TREVISANI, F. de M. (Orgs.) Ensino Híbrido: Personalização e Tecnologia na Educação. Porto Alegre: Penso, 2015. 270p.

BARBOSA, E. F.; MOURA, D. G. Metodologias ativas de aprendizagem na educação profissional e tecnológica. Boletim Técnico Senac, Rio de Janeiro, v. 39, n. 2, p. 48-67, maio/ago. 2013.

BARCElOS, A. M. F.; ABRAHÃO, M. H. V. Crenças e ensino de línguas. São Paulo: Pontes, 2006.

BECKER, D. V.; ÁVILA, LUCAS VEIGA; NASCIMENTO, L. F. M.; MADRUGA, L. R. R. G.. Educação para a sustentabilidade no Ensino Superior: O papel do docente na formação do Administrador. Revista Eletrônica em Gestão, Educação e Tecnologia Ambiental, v. 19, v. 19, n.3, set-dez 2015, p.615-628. Disponível em:<https://periodicos.ufsm.br/reget/article/viewFile/16413/pdf>. Acesso em: 13 mar. 2018.

BERGMANN, Jonathan; SAMS, Aaron. Sala de aula invertida: Uma metodologia ativa de aprendizagem. Trad. Afonso Celso da Cunha Serra. 1. ed. Rio de Janeiro: LTC, 2016.

Cartola - Agência de Conteúdo - Especial para o Terra. Sala de aula invertida tem aula em casa e tema na escola. On line. Disponível em: <https://www.terra.com.br/noticias/educacao/sala-de-aula-invertidatem-aula-em-casa-e-tema-na-escola,1684eee6359f4410VgnVCM4000009bcceb0aRCRD.html> Acesso: 21 mar 2018. 
CLARK, R. C.; MAYER, R. E-Learning and the science of instruction: proven guidelines for consumers and designers of multimedia learning. 3. ed. San Francisco: Pfeiffer, 2011.

COSTA, Marina Morena. Sala de aula invertida faz alunos aprenderem de forma livre. 3 de maio de 2016. On line. Disponível:

http://porvir.org/sala-de-aula-invertida-faz-os-alunos-aprenderem-de-forma-livre/ Acesso. 21 mar 2018.

HORN, Michael B.; STAKER, Heather. Blended: usando a inovação disruptiva para aprimorar a educação. Porto Alegre: Penso, 2015. 292 p.

KENSKI, V. M. Tecnologias e tempo docente. Campinas: Papirus, 2013.

LOPES, Marina. Em uma escola estadual de Campinas, as aulas de matemática se tornaram mais dinâmicas com exercícios e interações entre professores e alunos. 24 de agosto de 2015. On line. Disponível em: http://porvir.org/sala-de-aula-invertida-poupa-tempo-para-interessa/ Acesso: 21 mar 2018.

MOITA, Lopes. Pesquisa Interpretativista Em LA (1994) - Documents: https://docgo.net/moita-lopespesquisa-interpretativista-em-la-1994 Acesso jan 2018.

MORAN, J. M. Mudando a educação com metodologias ativas. In: SOUZA, C. A.; TORRESMORALES, O. E. (Orgs.). Convergências midiáticas, educação e cidadania: aproximações jovens. Ponta Grossa: UEPG, 2015. (Mídias Contemporâneas, v. 2). p. 15-33. Disponível em: Acesso em: 23 out. 2015.

MOREIRA, Luciano Accioly Lemos. A (In)sustentabilidade do discurso da educação para o desenvolvimento sustentável do Banco Mundial. ETD. Educação Temática Digital, v. 9, p. 20-30, 2008.

PRADO, A. Entendendo o aluno do século 21 e como ensinar a essa nova geração. São Paulo: Geekie, 2015. Disponível em: <https://cld.pt/dl/download/ b9bcdc77-a9cb-4cfd-af7cb7bb28895e7f/EBOOK_geekie_aluno21.pdf >. Acesso em: 10 out. 2015.

RAMAL, Andrea. Sala de aula invertida: a educação do futuro. 28 de abril 2015. On line. Disponível em: http://g1.globo.com/educacao/blog/andrea-ramal/post/sala-de-aula-invertida-educacao-do-futuro.html Acesso: 21 mar de 2018

SCHLÜNZEN JÚNIOR, K. Como a tecnologia pode contribuir para renovar a educação: porque precisamos adaptar nossas práticas a um cenário educacional em constante mudança? 2015. Painel apresentado pelo professor em parceria com pesquisadores e profissionais da área de educação no $1^{\circ}$ Congresso Bett Educar, São Paulo, 2015.

TALLEI, Jorgelina. Professora de espanhol fala do impacto na metodologia nas aulas da Universidade Federal da Integração Latino-Americana (UNILA). 14 de janeiro 2015. On line. Disponível em: http://porvir.org/sala-de-aula-invertida-da-autonomia-ao-aluno/ Acesso: 21 mar 2018. 
VALENTE, J. A. Blended learning e as mudanças no ensino superior: a proposta da sala de aula invertida. Educar em Revista, Curitiba, n. 4, p. 79-97, 2014. 